\title{
“JIKA DINDING BISA BERBICARA?" STREET ART DAN REPRESENTASI PEREMPUAN DALAM KARYA-KARYA STENSIL DIGIE SIGIT
}

\author{
Evan Sapentri \\ Mata Garuda, Alumni penerima Beasiswa Pendidikan Indonesia \\ Lembaga Pengelola Dana Pendidikan (LPDP), Kementerian Keuangan, RI \\ Email: evansapentri@yahoo.com
}

\begin{abstract}
This research examines Digie Sigit's stencil works in Yogyakarta. This paper focuses on explaining and understanding the material and immaterial aspects of Digie Sigit's stencil works along with analyzing women's representation form which is portrayed in his works. In collecting the research data, the researcher did observation by examining Digie Sigit's stencil works directly and doing deep interviews. Throughout his works, Digie Sigit wants to show appreciation and resistance of mothers as a heroine. He tries to create a possibility space where the public can see and directly meet his works. Women figures are chosen as power representation in earning money for living. They do not care when they are often ostracized and even do not get working assurance from the government. The public space is made as nowadays' city representation along with as critics about life, especially for the young generation of this country.
\end{abstract}

Keywords: Digie Sigit, Graffiti, Public Space, Stencil, Street Art

\begin{abstract}
ABSTRAK
Penelitian ini mengkaji karya-karya stensil Digie Sigit di Yogyakarta. Tulisan ini berikhtiar menjelaskan dan memahami aspek-aspek material dan imaterial karyakarya stensil Digie Sigit sekaligus menganalisis bentuk representasi perempuan yang digambarkan dalam karya stensil Digie Sigit. Dalam pengumpulan data penelitian, penulis melakukan observasi dengan mengamati karya-karya stensil Digie Sigit secara langsung dan melakukan wawancara mendalam. Melalui karyanya, Digie Sigit ingin menunjukkan apresiasi dan resistensi ibu-ibu sebagai pahlawan. Ia mencoba menciptakan ruang kemungkinan di mana publik bisa melihat dan bertemu langsung dengan karyanya. Figur perempuan dipilih sebagai representasi kekuatan dalam mencari nafkah tak peduli ia kerap dikucilkan bahkan tak diberikan jaminan kerja oleh pemerintah. Ruang publik dijadikannya sebagai representasi kota saat ini sekaligus sebagai kritik tentang kehidupan, terutama untuk anak-anak muda di negeri ini.
\end{abstract}

Kata kunci: Digie Sigit, Grafiti, Ruang Publik, Stensil, Street Art 


\section{PENDAHULUAN}

“...Banksy's artistic revolution will proceed to push society to pay attention to problems that plague the daily life of people everywhere," demikian kata Lexa Brenner (2019: 37). Sebagian orang mungkin masih ingat peristiwa mencengangkan yang terjadi pada 2018 silam di Sotheby's-sebuah perusahaan balai lelang seni yang bermarkas di New York. Ia adalah "Girl with Balloon," salah satu karya Banksy-seniman asal Inggris. Karyanya itu dilelang dengan harga fantastis, sekitar 1,3 juta dolar. Namun, nasib nahas menimpa karya itu. Ia "menghancurkan" dirinya sendiri sesaat setelah palu pelelang diketuk.

Anda boleh jadi bertanya-tanya demikian: "Mengapa karya stensil macam itu saja bisa laku sedemikian mahalnya?" Bagaimana menentukan indikator-indikator terkait penetapan harga lukisan? Bagaimana sebuah karya yang cuma disemprot menggunakan cat itu punya pesona sebegitu tingginya?

Anda barangkali dapat menemukan jawabannya dengan mengintip salah satu film bergenre thriller-psikologis yang tidak hanya menceritakan letupan emosi percintaan, namun juga mengedepankan pertunjukan lelang karya seni yang dikemas secara epik dan menggairahkan. Film itu berjudul "The Best Offer" (2013), besutan sutradara kawakan Giuseppe Tornatore. Anda juga dapat menyimak secara saksama disertasi Mikke Susanto yang berjudul "Pengembangan Indikator-Indikator Penetapan Harga Lukisan pada Panduan Penilaian Koleksi Karya Seni Istana Kepresidenan Republik Indonesia dan Implikasinya terhadap Wacana Seni" (2018), karena di artikel ini penulis tidak akan membahas perkara tersebut.

Banksy memang bukan seorang seniman biasa, dapat dikatakan kini ia menjelma menjadi ikon seni jalanan (street art) bagi sebagian seniman di dunia. Ini terbukti dari lahirnya "Banksy Effect," sebuah gejolak yang menggambarkan dan melambungkan popularitas seni jalanan musabab dari ketenaran si Banksy sendiri (Brenner, 2019: 37). Gejala serupa sempat mewarnai dinding-dinding di tiap sudut kota di dunia, termasuk di beberapa negara di Timur Tengah. Mayoritas negara di Timur Tengah mengalami pergolakan internal seperti kondisi sosial, politik, juga ekonomi yang berbeda-beda di satu negara. Terhitung dari akhir tahun 2010awal 2011 tercatat pecahnya gelombang revolusi masyarakat Timur Tengah yang dikenal dengan sebutan "Arab Spring" melanda beberapa negara di wilayah tersebut termasuk Mesir (Putri, 2015: 2).

Menyikapi hal tersebut, dalam penelitian yang serupa, Adrienne de Ruiter (2015), menyebutkan bahwa grafiti dapat digunakan sebagai salah satu media komunikasi sekaligus bentuk kontra dengan pemerintah Mesir (official media). Para seniman di Mesir memilih street art untuk menangkal propaganda pemerintah, dengan meninggalkan bukti dan menjelaskan mengenai apa yang sebenarnya terjadi melalui teks, tipografi, tulisan, gambar (painting), dan grafis. Melalui street art, para seniman dapat membuat orang berpikir tentang apa yang sedang terjadi di media, melawan media dengan menciptakan realitas dengan cara memprotes dan menyebarkan pesan dengan tujuan memobilisasi orang-orang. Street art dan grafiti 
inilah yang memberikan peluang akan terciptanya ruang-ruang interaksi dan dialog.

Menurut Rancière dalam de Ruiter (2015), praktik-praktik artistik macam itu setidaknya mampu memainkan peran politik, karena memengaruhi (re)distribution of the sensible. Praktik-praktik artistik itu selanjutnya mampu membingkai ulang hubungan antara ruang dan waktu, subjek dan objek, yang umum dan yang tunggal. Seni pada akhirnya, dapat bersifat politis karena dapat mengubah cara kita melihat dunia dan mampu menunjukkan apa yang tidak terlihat.

Beranjak dari geliat wacana di atas, di beberapa kesempatan sosok perempuan memang kerap kali menjadi figur "politis" yang dipercaya berhasil menyuarakan keresahan si seniman. Adakalanya lewat figur atau teks-teks berbau seks terkadang menjadi muatan "wajib" di sebagian kalangan. "Women who would like to have sex with me, please call me. I would like to have a boyfriend and have sex with him. Response: I am interested. Please write me with the following email address" (Zenebe, 2018: 99).

Street art merupakan salah satu media untuk mengkritik dan memang bukan suatu hal yang baru. Teks di atas apabila dicermati berisi muatan intim seseorang yang sedang "merindukan" seks. Namun, sesungguhnya lewat teks itu, kita dapat belajar bahwa menggumbar masalah seks di muka umum merupakan suatu tindakan tak bermoral. Menurut Foucault (1978), dalam konteks doktrin Kristen kenikmatan terhadap "daging" itu terkadang dianggap jahat dan berdosa yang harus ditinggalkan. Oleh karena itu, melindungi diri dari hasrat seksual terkadang dianggap sebagai cara ampuh untuk melindungi diri dari kejahatan dunia.

Serba-serbi permasalahan sosial, politik, dan ekonomi turut meramaikan tema-tema street art. Hal itu pun turut memengaruhi cara-cara seniman meluapkan ide kreatifnya. Salah satu seniman itu adalah Digie Sigit. Ia adalah seorang seniman stensil sekaligus rapper dari sebuah kelompok musik asal Yogyakarta bernama Teknoshit. Digie Sigit mengawali kegiatan berkeseniannya dalam bidang seni grafis dan aktif memotret kejadiankejadian di sekitar yang berhubungan dengan kehidupan sosial dan politik (Lotan, 2015: 15).

Beberapa karya Digie Sigit mengangkat isu-isu sosial (karya "Negeriku Tidak Dijual," 2014, yang menceritakan penjualan lahan pertanian untuk pembangunan hotel), isu ekonomi (karya "Sebuah Catatan Tentang Keadilan Ekonomi," 2015, yang menceritakan permasalahan kesenjangan ekonomi), dan isu sejarah (karya "Sejarah Itu Penting," 2015, yang menceritakan beberapa bagian sejarah Indonesia yang mulai dihapuskan dari rangkaiannya) (Setyowati, 2016).

Selain itu, tak jarang pula Sigit menuliskan kata-kata di beberapa karyanya. Bahkan, sosok anak-anak dan perempuan kerap kali melengkapi sebagain besar narasi cerita di karya stensilnya.

Objek materiel dalam penelitian ini akan berfokus pada dua karya Digie Sigit yang merepresentasikan figur Mbok Srumbung. Mbok merupakan kata sapaan atau panggilan untuk nenek dalam Bahasa Jawa. Mbok Srumbung tidak hanya digambarkan sebagai sosok perempuan tua, tapi juga diartikan sebagai (nama pekerjaan), atau pekerjaan yang dilakukan Mbah 
Ratmi di Pasar Beringharjo, Yogyakarta. Penulis memilih figur Mbok Srumbung dalam karya Digie Sigit karena belum ada penelitian yang menganalisis objek penelitian ini, terutama kajian mengenai media yang digunakan Digie Sigit yaitu kotak trafo Perusahaan Listrik Negara (PLN). Bagi penulis pemilihan media ini unik dan cukup jarang dilakukan oleh seniman.

Dua karya yang penulis pilih diaplikasikan di media yang berbeda. Karya tersebut yakni; (1) di dinding luar Stadion Kridosono Yogyakarta, dan (2) di kotak trafo PLN di Pasar Prawirotaman, di depan Pasar Klithikan Pakuncen, dan di jalan P. Mangkubumi.

Lebih jauh penulis juga akan mencermati objek formal dalam penelitian ini yakni representasi Mbok Srumbung sebagai perempuan sekaligus sebagai pekerja yang diangkat si seniman dalam karyanya. Mengapa Mbok Srumbong dipilih, kenapa Digie Sigit memilih kotak trafo PLN sebagai salah satu media untuk berkarya, bagaimana ia mewujudkannya dan untuk siapa karya ini ditujukan; perempuan, anakanak, masyarakat atau negara?

Tulisan ini berikhtiar menjelaskan dan memahami aspekaspek materiel dan imateriel dalam karya stensil Digie Sigit sekaligus menganalisis bentuk representasi perempuan yang digambarkan dalam karya stensil Digie Sigit. Secara teoretis penelitian ini diharapkan dapat menambah referensi studi interdisiplin seni rupa dengan menyuguhkan kajian mengenai keterkaitan antara seni dan gender, maupun singgungan antara seni dan politik. Penelitian ini juga diharapkan dapat dijadikan bahan diskusi, dikritisi, dan dikembangkan oleh peneliti-peneliti berikutnya yang tertarik dalam bidang seni rupa.

\section{STUDI LITERATUR}

Seperti yang telah disinggung di atas bahwa kajian mengenai media yang digunakan Digie Sigit yaitu kotak trafo PLN masih amat jarang digunakan bagi kebanyakan seniman jalanan di Yogyakarta. Poin itu menjadi pijakan penulis sebagai pembanding atas tulisan ini, selain memperkaya disiplin ilmu, diharapkan penulis juga tidak terjebak dalam analisis dan perspektif serupa. Oleh sebab itu, penulis perlu menelusuri beberapa literatur sebagai berikut.

Sebuah artikel yang berjudul "Graffiti sebagai Pengisi Ruang Komunikasi Simbolik Seni Jalanan Masyarakat Urban" (2013) yang ditulis oleh Rudy Harjanto dan Setiawan Sabana. Dalam tulisannya, Harjanto dan Sabana menjelaskan mengenai kesemarakan ruang-ruang kota berkat kehadiran karya-karya seni jalanan. Karya seni jalanan itu tidak hanya memanjakan mata dari segi visual, namun berkatnya ruang-ruang kota mampu menjelma menjadi ruang pamer. Fenomena itu sekaligus menjelaskan bahwa penerimaan masyarakat urban terhadap ruang kini berubah. Hal yang demikian itu akhirnya berpotensi memberikan daya ruang publik sebagai bentuk komunikasi simbolik.

Tulisan Harjanto dan Sabana memberikan tawaran bagaimana proses kreatif si seniman itu mampu dinegosiasikan oleh masyarakat urban lewat grafiti. Beranjak dari gejala di atas, isu-isu sosial dan ekonomi, atau sejarah juga telah disinggung dalam tulisan lainnya seperti dari Nurmala Setyowati dalam tulisannya yang 
berjudul "Kajian Semiotik Karya-Karya Stensil Propaganda Digie Sigit” (2016).

Objek materiel yang diteliti mempunyai kesamaan dengan penelitian ini yakni karya stensil Digie Sigit yang menggunakan media kotak trafo PLN, namun dengan objek gambar yang berbeda. Penelitian tersebut menggunakan teori semiotika Charles Sanders Peirce yakni ikon, indeks dan simbol.

Berbicara mengenai seni jalanan, Syamsul Barry dalam bukunya "Jalan Seni Jalanan Yogyakarta” (2008) telah mengupas telaah mengenai seni jalanan itu sendiri hingga perkembangannya di Yogyakarta. Tulisan serupa turut melengkapi studi literatur dalam penelitian ini yakni buku yang berjudul "Banksy: Urban Art in a Material Word" (2016) dari Ulrich Blanché. Kedua literatur di atas berguna bagi penulis dalam memperkaya khasanah ilmu tentang kajian mengenai istilah grafiti dan street art, terutama dalam bukunya Blanché di Bab ke-2.

Buku dari Cedar Lewisohn yang berjudul "Street Art The Graffiti Revolution" (2008) juga tidak kalah menarik dengan literatur sebelumnya. Jika Barry dan Blanché banyak memaparkan perkara term grafiti, street art, dan urban art, di bukunya itu Lewisohn banyak menunjukkan praktik-praktik seni jalanan di beberapa penjuru dunia dengan menampilkan karya-karya seniman kenamaan seperti Rowdy, Jorge Rodriguez, Barry McGee, John Fekner, Keith Haring, Jean-Michel Basquiat, dan karya-karya seni jalanan simbolik dari seniman anonymous lainnya. Lewisohn tidak hanya mampu mencuri pemirsa dengan suguhan gambargambar visual dalam bukunya itu, sesekali ia berupaya mendeskripsikan dan menganalisis gambar-gambar tersebut. Hal itu menjadi penting karena penulis diberikan jalan dan cara-cara membaca karya seni jalanan yang tentunya sangat berelasi dengan topik yang dikaji dalam tulisan ini.

Buku yang ditulis secara komprehensif oleh Alison Young, berjudul "Street Art, Public City: Law, Crime and The Urban Imagination" (2014) juga menarik untuk ditelaah. Tulisannya di Bab 5 dan 6 berhasil mencuri mata penulis. Ia memaparkan seni jalanan dan politik ruang serta transformasi-imajinasi perkotaan di kota (public city) dengan begitu menggugah. Hal itu memperkaya penulis dalam menelaah perkara singgungan antara ruang privat dan publik.

Artikel yang membantu penulis dalam membedah karya dengan menggunakan teori materiality dan immateriality dari Nicholas Alden Riggle juga perlu ditambahkan sebagai literatur. Tulisan Tony Chackal yang berjudul "Of Materiality and Meaning: The Illegality Condition In Street Art" (2016) menjadi pijakan penulis dalam mendeskripsikan, menganalisis, menafsirkan, dan menilai karya stensil Digie Sigit.

Selain literatur di atas, peneliti perlu memahami relasi antara seni dan politik. Oleh karena itu, artikel yang berjudul "Imaging Egypt's Political Transition In (Post-) Revolutionary Street Art: on The Interrelations Between Social Media and Graffiti As Media of Communication" (2015) dari Adrienne de Ruiter penting untuk dijadikan pijakan dalam telaah penelitian ini.

Dalam tulisannya itu, de Ruiter ingin melihat keterkaitan antara street art dan media sosial, mengapa orangorang (pemuda) yang terlibat secara 
politik di Kairo, Mesir memilih grafiti sebagai media ekspresi politik mereka? Padahal ada media komunikasi lain seperti Facebook dan Twitter.

Grafiti digunakan sebagai media komunikasi sebagai bentuk kontra dengan pemerintah (official media). Pemerintah Mesir mengendalikan berbagai media seperti televisi, radio, koran dan majalah. Media digunakan untuk melawan revolusi. Laporan dari media merupakan salah satu bentuk propaganda negara. Para seniman memilih street art untuk menangkal propaganda pemerintah dengan meninggalkan bukti dan menjelaskan mengenai apa yang sebenarnya terjadi melalui teks, tipografi, tulisan, gambar (painting), dan grafis. Melalui grafiti, para seniman dapat membuat orang berpikir tentang apa yang sedang terjadi di media, melawan media dengan menciptakan realitas dengan cara memprotes dan menyebarkan pesan dengan tujuan memobilisasi orang-orang.

Tulisan-tulisan di atas menjadi tinjauan literatur penulis karena selain menghindari potensi adanya plagiat, penulis juga ingin memperkaya sudut pandang dalam penelitian ini melalui penelitian-penelitian sebelumnya. Hal tersebut semakin medorong dan memberikan semangat kepada penulis untuk menganalisis karya stensil Digie Sigit secara lebih detail. Diharapkan tinjauan literatur di atas semakin memperkuat argumentasi tulisan ini secara lebih komprehensif-tekstual dan kontekstual.

\section{METODE PENELITIAN}

Karya-karya Digie Sigit akan dianalisis dengan mencermati Material Requirement dan Immaterial Requirement dari Nicholas Alden Riggle (2010). Material Requirement mengacu pada penggunaan sumbersumber artistik (artistic resources), yaitu berkaitan dengan materialmaterial fisik, seperti pelukis ketika menggunakan cat dan kanvas, dalam hal ini Digie Sigit menggunakan elemen jalanan, dinding dan kotak trafo PLN. Kedua, konteks di mana karya tersebut ditampilkan, bisa menggunakan galeri, studio, atau museum, dalam hal ini Digie Sigit sebagai salah satu seniman jalanan menggunakan jalan untuk merepresentasikan karyanya. Immaterial Requirement mengacu pada interpretasi atau penafsiran sebuah karya seni jalanan yang mengacu pada cara si seniman menggunakan jalan dalam memberikan pemaknaan terhadap karyanya (Riggle, 2010: 245246).

Dalam pengumpulan data penelitian, penulis mengandalkan proses observasi dengan mengamati karya stensil Digie Sigit secara langsung dan mendokumentasikannya. Observasi itu bertujuan untuk mengamati secara visual gejala yang diamati agar dapat menginterpretasikan hasil pengamatan tersebut secara saksama (Widoyoko, 2014: 46). Observasi secara langsung didukung dengan wawancara mendalam (deep interview) bersama Digie Sigit. Wawancara mendalam dipilih guna memperoleh informasi maupun data yang berkaitan dengan objek penelitian serta menggali pengalaman estetiknya dalam berkarya dengan mengajukan beberapa pertanyaan tidak terstruktur.

\section{HASIL DAN PEMBAHASAN}

Seni jalanan mulai marak muncul di Yogyakarta pada tahun 2000-an dan merupakan perkembangan dari grafiti. Kata "jalanan" pada seni jalanan 
mengandung arti tanpa aturan, vandal atau ilegal, menang-menangan. Kini grafiti lebih dikenal sebagai seni jalanan (street art). Grafiti tidak lagi berupa coretan teks, tetapi juga digabungkan dengan gambar yang dihasilkan dari penggunaan teknik yang beragam (stiker, wheatpaste, poster, stensil) (Barry, 2008).

Seni grafiti adalah proses menulis atau menggambarkan kata yang dituliskan, dilukiskan, digoreskan, atau disemprotkan di dinding atau permukaan lain di suatu tempat umum. Material bahan yang sering digunakan adalah cat yang berbasis minyak maupun cat berbasis air, bahkan media lain seperti spidol, kertas, dan stiker yang sajikan pada dinding atau permukaan lain di ruang-ruang terbuka, seperti dinding jalan layang, jembatan, dan sebagainya (Harjanto dan Sabana, 2013: 415).

Street art merupakan sub-genre dari grafiti. Grafiti merupakan bentuk jamak dari graffito yang berarti gambar atau teks di dinding. Keduanya berbeda secara bentuk, fungsi, dan pemaknaannya. Karakter dari grafiti secara umum menggunakan cat semprot (spray paint), sedangkan street art lebih fokus pada penerapan simbol-simbol visual (Lewisohn, 2018). Oleh karena itu, perlu menelaah lebih teliti karya-karya stensil Digie Sigit. Proses untuk melihat representasi perempuan yang digambarkan si seniman juga akan ditelaah dengan mencermati karyakarya Digie Sigit sebagai berikut.

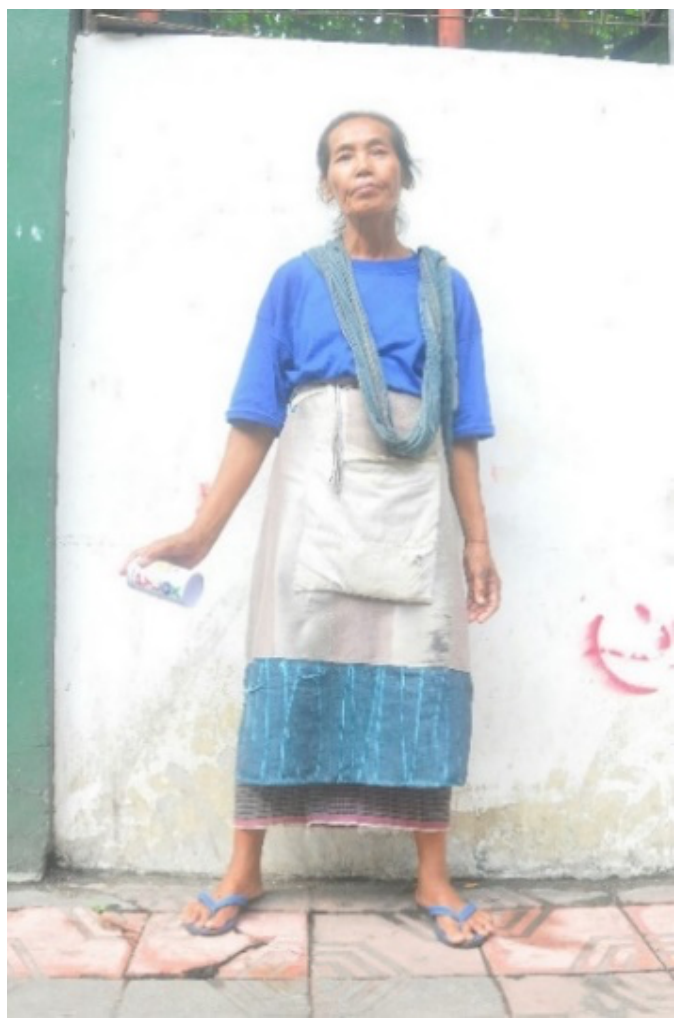

Gambar 1. Mbok Srumbung (Foto: Digie Sigit, 2017)

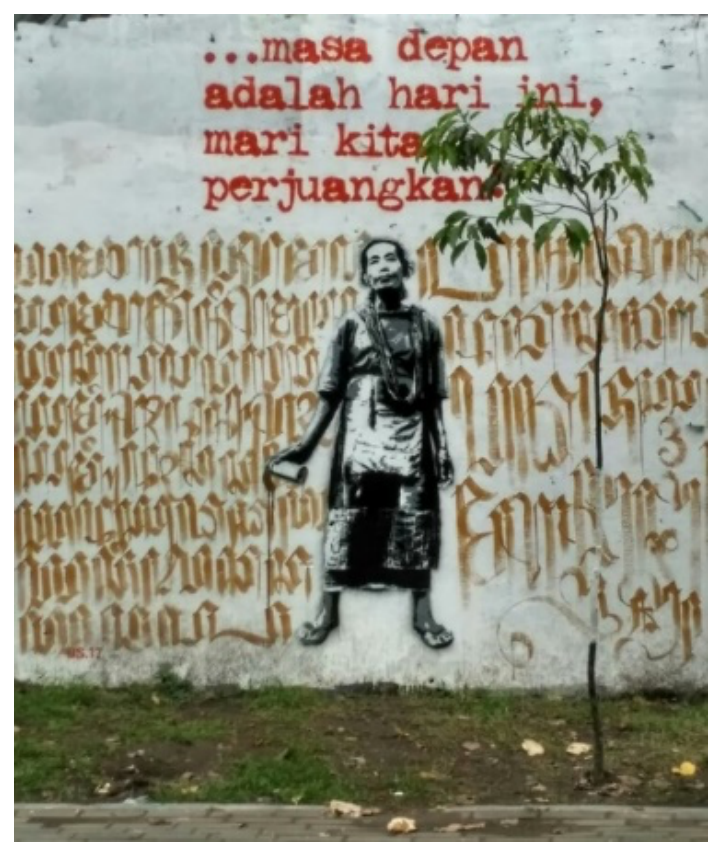

Gambar 2. Digie Sigit, Masa Depan adalah Hari Ini, Karya Stensil di Dinding

(Foto: Evan Sapentri, 2017) 
Gambar 1 di atas menunjukkan Mbok Srumbung yang sedang memegang sebuah sprayer berwarna putih di tangan kanannya. Ekspresi kaku dengan badan tegap, baju biru yang rapi dimasukkan ke dalam rok yang tampak kumuh, sementara seutas selempang panjang terlihat memeluk kedua bahunya, dengan dilengkapi sandal berwarna biru yang menjepit erat di kedua kakinya.

Teknik stensil dipilihnya dengan menggunakan warna hitam putih. Cat yang disemprotkannya sebenarnya berwarna hitam. Kesan warna putih yang terlihat di gambar tersebut berkat teknik gelap terang. Teknik stensil biasanya menggunakan cetakan sebagai alatnya. Cetakan yang dimaksud bukan cetakan yang biasa dipakai untuk membuat roti. Kertas adalah salah satu media yang bisa dipakai. Sebelum seniman menyemprotkan catnya, pemberian pola tetap di kertas kerap kali dilakukan seniman, seperti karya stensil Digie Sigit di atas. Pola tetap itulah yang akan dijadikan cetakan dalam berkarya.

Teknik stensil dipilih oleh sebagian seniman karena dianggap lebih mudah diaplikasikan di beberapa media seperti dinding, sekaligus menghasilkan gambar secara langsung di dinding, dan mudah direproduksi ulang. Teknik serupa juga dilakukan oleh beberapa seniman di dunia seperti; Conor Harrington, Bansky, FAILE, Logan Hicks, Blek re Lat, D*Face, Paul Insect, Os Gemeos, dan seniman anonymous lainnya (Hundertmark, 2010; McAvera, 2014; Cowick, 2015; Nash, 2019).

Figur Mbok Srumbung tak ada yang berubah dari gambar aslinya. Mata pun tersedot dengan tulisan warna merah yang berbunyi: Masa depan adalah hari ini, mari kita perjuangkan, yang tajam kontras dengan warna sang figur. Mbok Srumbung merupakan salah satu representasi perempuan masa kini yang tetap sabar menjalani profesinya di pasar Beringharjo, Yogyakarta. Walaupun sampai detik ini tidak diakui sebagai profesi atau bahkan diberikan jaminan kerja oleh pemerintah. Tembok di stadion Kridosono sebagai saksi bisu di mana karya ini dipresentasikan. Tempat yang sangat representatif di mana kendaraan dan publik berlalu-lalang, event dan berbagai kegiatan bertemu, serta berbagai komunitas dan generasi saling bercengkerama di stadion ini. Gagasan ruang (public space) secara tradisional sebenarnya mengacu pada sesuatu yang anonim, sedangkan tempat (space) adalah fusi tatanan manusia dan alam serta merupakan pusat penting dari pengalaman langsung kita di dunia (Visconti, et.al., 2010: 512).

Seniman kerap kali menggunakan simbol-simbol tertentu dalam berkarya, seperti Bendera Nasional Timor Leste yang sempat terpampang di dinding kota Dili sebagai simbol resistensi, kekuatan, ekspresi identitas dan budaya ketika pendudukan ilegal di Indonesia berlangsung (Arthur, 2016). Selain itu, berbagai macam aksi seni jalanan (street art) dijadikan seniman untuk mengekspresikan diri dalam merespons kondisi sosial, ekonomi, dan politik sebuah negara. Salah satu contohnya adalah ketika Revolusi Mesir 2011 bergejolak, di mana berbagai media seperti televisi, radio, koran dan majalah di kendalikan oleh pemerintah Mesir. Para seniman pun mencari alternatif media lain untuk menyampaikan pesan-pesan 
politisnya, salah satunya melalui seni jalanan (de Ruiter, 2015). Di Dakar misalnya, grafiti tidak pernah berstatus ilegal. Semua orang dapat berkarya grafiti di jalanan (dinding-dinding) (Rabine, 2014).

Hal ini tentu tidak terlepas dari konteks keberadaan di mana karya dipresentasikan di ruang publik dan untuk tujuan apa karya dibuat. Dalam praktiknya, jika tidak dalam hukum dan teori hukum pidana, penilaian mengenai kriminalitas grafiti dibentuk oleh genre atau gaya, kompetensi artistik, keterbacaan, penempatan, keadaan degradasi, hubungan sosialartistik yang terkait dan konteks sosiopolitik (Kane, 2009: 10).

Dalam penelitian lain misalnya,

Miyase Christensen menyatakan bahwa street art memang untuk masyarakat secara umum. Tak jarang pula seniman menggunakan media sosial sebagai cara lain untuk mengekspansi pesan-pesan dan isu-isu yang diangkat si seniman. Namun, bagi kebanyakan seniman ada keterbatasan untuk bersuara di media sosial, kita bisa memilih target siapa yang akan menerima, apa yang akan kita publikasikan dan ekspos lewat media sosial. Melalui street art semua kalangan dari anak-anak, remaja, orang dewasa, hingga lansia dapat melihat dan menikmati karya (Christensen dan Thor, 2017). Hal itu lah yang juga dilakukan Digie Sigit. Baginya, karya stensil di pinggirpinggir jalan itu diharapkan dapat dibaca oleh masyarakat lintas umur, lintas pekerjaan, dan lintas strata.

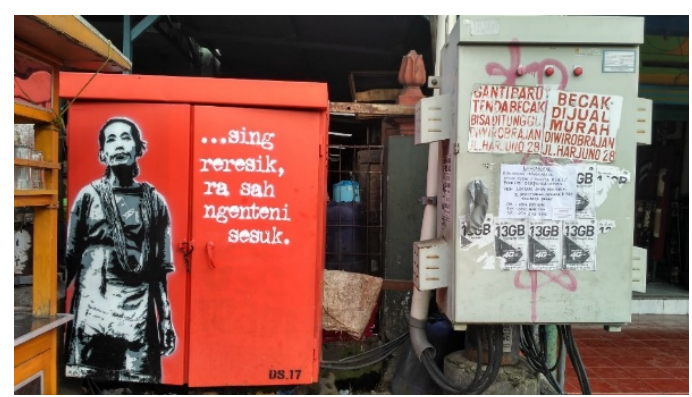

Gambar 3. Digie Sigit, seng reresik ra sah ngenteni sesuk, Karya Stensil di kotak trafo PLN, pasar Prawirotaman (Foto: Evan Sapentri, 2017)

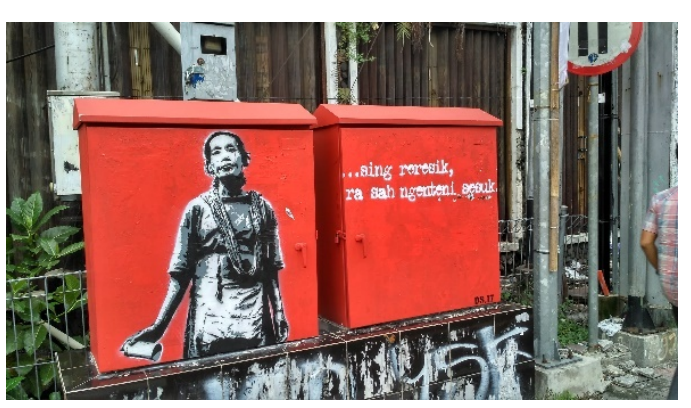

Gambar 4. Digie Sigit, seng reresik ra sah ngenteni sesuk, Karya Stensil di kotak trafo PLN, jalan P. Mangkubumi (Foto: Evan Sapentri, 2017)

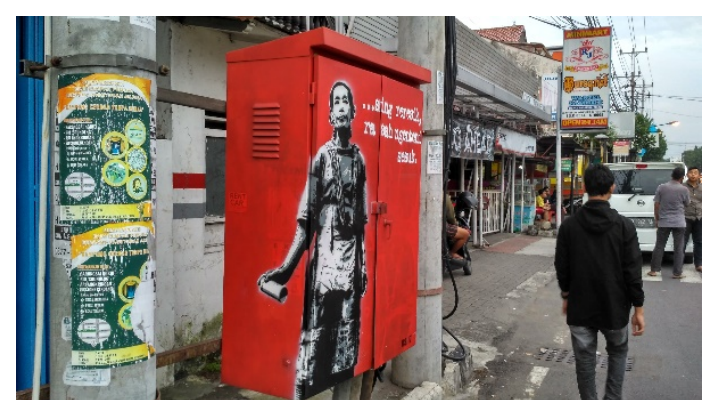

Gambar 5. Digie Sigit, seng reresik ra sah ngenteni sesuk, Karya Stensil di kotak trafo PLN, di depan Pasar Klithikan Pakuncen (Foto: Evan Sapentri, 2017)

Dari gambar di atas Digie Sigit mencoba bereksperimen dengan media baru dalam berkarya. Kotak trafo PLN sebagai representasi negara 
dalam menengahi permasalahan sosial dan politik. Jika dilihat lebih dekat, terlihat bekas poster, kertas, tulisan yang menempel di kotak trafo PLN. Kata-kata, kalimat, isi atau konten yang terpampang menjadi konsumsi publik.

Tak jarang Digie Sigit menemukan muatan negatif untuk konsumsi anak-anak yang membingkai kotak trafo PLN tersebut, seperti iklaniklan memperpanjang alat kelamin, sedot WC, pelatihan hipnotisme, dan lain sebagainya. Hal itu menggelitik hatinya untuk menanamkan pesanpesan yang baik dengan menggantikannya dengan karyanya.

Tujuan menuliskan kata-kata di karya stensilnya adalah untuk mengangkat dan mendistribusikan isuisu positif di ruang publik. Misalnya seng reresik, ra sah ngenteni sesuk, merupakan ungkapan, ajakan, dan motivasi si seniman untuk mengajak masyarakat agar bersama-sama, bahumembahu melakukan segala sesuatunya sekarang tidak perlu menunggu besok. Ia juga ingin menghapus "visual terror" yang menempel di properti PLN di pinggirpinggir jalan atau di tembok-tembok jalanan yang baginya bisa merusak moral anak-anak.

Bagi penulis, karya stensil Digie Sigit sebenarnya tidak menunjukkan suatu aksi, reaksi, atau tindakan perempuan yang sedang berjuang mencari nafkah. Ekspresi yang datar sementara sprayer digenggam ditangannya butuh penafsiran lebih dalam. Oleh sebab itu, karya itu baru "bunyi" setelah ada penambahan katakata dari si senimannya. Ia bahkan tak ada bedanya dengan sebuah gambar tanpa arti jika kata-katanya dihapus. Orang yang tak sengaja melihat mungkin akan sekadar bertanya dalam hati, "sosok siapa kah ini?" Ini tentu menarik karena bagi sebagian seniman seperti Bansky gambar memang punya daya pikat utama ketimbang bermain dengan tataran kata-kata puitis. Hal itu justru berbanding terbalik, antara teks dan gambar dari karya di atas saling melengkapi-tanpa keduanya ia tak punya daya apa-apa.

Apabila karya tersebut ditinjau dari segi legalitas, maka permasalahan legalitas penggunaan "jalan" sebagai tempat berkesenian mungkin belum terpikirkan oleh wakil-wakil rakyat kita di Senayan, Jakarta. Tampaknya Undang-Undang Nomor 26 tahun 2007 tentang Penataan Ruang belum sepenuhnya merapikan persoalan tersebut. Tak salah juga jika beberapa seniman seperti Digie Sigit kerap mengeksploitasi jalanan sebagai ruang alternatif untuk menyuarakan keluh kesahnya. Selain memang dindingdinding atau kotak trafo PLN dibiarkan teronggok begitu saja, seniman malah bisa menghemat pembelian kanvas untuk melukis dan menyalurkan ide kreatifnya.

Seni jalanan di satu sisi juga berpeluang menciptakan ruang negosiasi antara si pemilik "kanvas" dengan si senimannya. Namun, jika negosiasi tak berakhir baik, jalan sunyi dapat ditempuh, yakni dengan memodifikasi dinding-dinding; menambahkan ornamen tertentu atau dibuat bertekstur. Hal itu dilakukan untuk merespons seniman jalanan yang kerap usil. Lebih ekstrimnya lagi, dinding-dinding yang kerap disemprot itu terkadang dirobohkan oleh pemiliknya (McAuliffe, 2013: 529).

Berdasarkan beberapa telaah di atas, karya-karya Digie Sigit yang dikaji dalam tulisan ini cenderung mendekati karya street art, walaupun tidak sepenuhnya bisa dikatakan demikian sebab selain kuat dengan penggunaan 
simbol (gambar) perempuan, ia juga menyematkan kata-kata di beberapa karyanya. Kata-kata tersebut juga bisa dibaca jelas tanpa perlu mencermatinya lebih detail. Selain itu, tulisannya pun mudah dipahami sehingga ia memiliki potensi untuk "berinteraksi" dengan publik. Hal itu berbeda dengan grafiti yang mempunyai kecenderungan persoalan dalam hal keterbacaan teks, seperti apa yang disampaikan oleh FAILEseniman kolaboratif asal Brooklyn, New York, bahwa: "Street art is more about interacting with the audience on the street and the people, the masses. Graffiti isn't so much about connecting with the masses: it's about connecting with different crews, it's an internal language, it's a secret language. Most graffiti you can't even read, so it's really contained within the culture that understands it and does it. Street art is much more open. It's an open society" (Lewisohn, 2008: 15).

\section{KESIMPULAN}

Melalui Mbok Srumbung ini Digie Sigit sebenarnya ingin melihat apresiasi dan resistensi ibu-ibu sebagai pahlawan. Ide inilah yang memberikan inspirasi dirinya untuk berkarya. Digie Sigit juga mencoba menciptakan ruang kemungkinan di mana publik bisa melihat dan bertemu langsung dengan karyanya. Beberapa karyanya menyebar di beberapa titik seperti di pasar Prawirotaman, pasar Klithikan Pakuncen, stadion Kridosono, dan di jalan P. Mangkubumi. Baginya ibu-ibu ini merupakan suri teladan. Figur perempuan dipilih sebagai representasi kekuatan dalam mencari nafkah tak peduli ia kerap dikucilkan bahkan tak diberikan jaminan kerja oleh pemerintah.
Ruang publik sebagai representasi kota kita saat ini, kritik tentang anak muda, tentang masa depan hari ini dengan harapan sesuai dengan konteks pemuda saat ini yang tidak patuh kepada orang tua dan lain sebagainya. Melalui karya ini ia sangat bahagia karena karyanya bisa disentuh oleh publik secara langsung di jalan. Potensi grafiti untuk menciptakan jendela yang terbuka penting untuk dikenali, memperluas cakrawala visual dan ruang budaya kota (Kane, 2009: 11).

Melalui seni grafis dengan teknik stensil ia mencoba membuat karya street art dengan menggunakan dinding dan kotak trafo PLN sebagai medianya sekaligus sebagai bentuk representasi negara dalam menjawab segala tantangan sosial, politik, dan ekonomi. Mengenai legalitas karya seni yang dipresentasikan di ruang publik, apakah risiko dan bahaya yang ditimbulkan ketika membuat karya seni, atau justru karena keberanian si seniman? Hal ini belum banyak disinggung dalam menganalisis sebuah karya seni jalanan, khususnya di Indonesia.

\section{UCAPAN TERIMA KASIH}

Penulis mengucapkan terima kasih kepada Digie Sigit (seniman) yang telah memberikan izin melakukan wawancara serta mengakses dan menggunakan fotofoto karya stensilnya, sehingga penulis dapat merampungkan tulisan ini. Wawancara tersebut bertepatan dengan Biennale Forum-salah satu rangkaian kegiatan Biennale Jogja keXIV (2017) yang digelar di Ruang Seminar Pascasarjana, Institut Seni Indonesia Yogyakarta pada 9 Desember 2017. 


\section{DAFTAR PUSTAKA}

Arthur, C. (2016). Painting Their Past: The Geracao Foun, Street Art and Representating Notions of "East Timorese-ness," Journal of Social Issues in Southeast Asia, 31(1), 173-206. http://dx.doi.org/10.1355/sj $31-1 \mathrm{e}$

Barry, S. (2008). Jalan Seni Jalanan Yogyakarta. Yogyakarta: Studium.

Blanché, U. (2016). Banksy: Urban Art in a Material World (Terjemahan oleh Rebekah Jonas and Ulrich Blanché). Marburg, German: Tectum Verlag.

Brenner, L. (2019). The Bansky Effect: Revolutionizing Humanitarian Protest Art, Harvard International Review, 40(2), 34-37. http://dx.doi.org/10. $2307 / 26617408$

Chackal, T. (2016). Of Materiality and Meaning: The Illegality Condition in Street Art, The Journal of Aesthetics and Art Criticism, 74(4), 359-370. http://dx.doi.org/10.1111/ja ac. 12325

Christensen, M., \& Thor, T. (2017). The Reciprocal City, Performing Solidarity-Mediating Space through Street Art and Graffiti, The International Communication Gazette, 79(67), 584-612. http://dx.doi.org/10.1177/17 48048517727183

Cowick, C. (2015). Preserving Street Art: Uncovering the Challenges and Obstacles. Art Documentation: Journal of the Art Libraries Society of North America, 34(1), 29-44. http://dx.doi.org/10.1086/68 0563

de Ruiter, A. (2015). Imaging Egypt's Political Transition In (Post-) Revolutionary Street Art: on The Interrelations Between Social Media and Graffiti As Media of Communication, Media, Culture, and Society, 37(34), 581-601. http://dx.doi.org/10.

1177/0163443714566901

Foucault, M. (1978). The History of Sexuality. Volume 1 (Terjemahan oleh Robert Hurley). London: Penguin Books.

Harjanto, R., \& Sabana, S. (2013). Graffiti sebagai Pengisi Ruang Komunikasi Simbolik Seni Jalanan Masyarakat Urban, Jurnal Panggung, 23(4), 410-422. http://dx.doi.org/10.267 42/panggung.v23i4

Hundertmark, C. (2010). The Art of Rebellion III: The Book about Street Art. Berkeley, CA: Gingko Press Inc.

Kane, S. C. (2009). Stencil Graffiti in Urban Waterscapes of Buenos Aires and Rosario, Argentina, Crime Media culture, 5(1), 1028. http://dx.doi.org/10.1177 /1741659008102060

Lewisohn, C. (2008). Street Art The Graffiti Revolution. London: Tate Publishing.

Lotan, F. F. (2015). Analisis Semiotika Penggunaan Estetika Foto Potret dalam Seni Stensil Digie Sigit (Skripsi). ISI Yogyakarta.

McAuliffe, C. (2013). Legal Walls and Professional Paths: The Mobilities of Graffiti Writers in Sydney. Urban Studies, 50(3), 518-537. 
http://dx.doi.org/10.

1177/0042098012468894

McAvera, B. (2014). Wall Power, Irish Arts Review, 31(1), 88-91. https://www.jstor.org/stable /24366345

Nash, G. (2019). Breaking All The House Rules: The Politics and Grammar of Disrespecting Contemporary Graffiti. Dalam Nash G. \& Huntley J. (Ed.), Aesthetics, Applications, Artistry and Anarchy: Essays in Prehistoric and Contemporary Art: A Festschrift in honour of John Kay Clegg, 11 January 1935-1 March 2015 (129141). Summertown, Oxford: Archaeopress. http://dx.doi. org/10.2307/j.ctvndv846.15

Putri, R. M. E. (2015). Pengaruh Media Sosial Facebook Terhadap Jatuhnya Rezim Pemerintahan Hosni Mubarak Di Mesir Tahun 2011, JOM FISIP, 2(2), 1-12.

Rabine, L. W. (2014). "These Wall Belong to Everybody" The Graffiti Art Movement in Dakar, African Studies Quarterly, 14(3), 90-112.

Riggle, N. A. (2010). Street Art: The Transfiguration of The Commonplaces, The Journal of Aesthetics and Art Criticism, 68(3), 243-257. https://www. jstor.org/stable/40793266

Setyowati, N. (2016). Kajian Semiotik Karya-karya Stensil Propaganda Digie Sigit, Jurnal
Pendidikan Seni Rupa UNY, 1, 1-9.

Susanto, M. (2018). Pengembangan Indikator-Indikator Penetapan Harga Lukisan pada Panduan Penilaian Koleksi Karya Seni Istana Kepresidenan Republik Indonesia dan Implikasinya terhadap Wacana Seni (Disertasi). Universitas Gadjah Mada, Yogyakarta.

Visconti, L. M., Sherry JR., J. F., Borghini, S., \& Anderson, L. (2010). Street Art, Sweet Art? Reclaiming the "Public in Public Place", Journal of Consumer Research, 37(3), 511-529. http://dx.doi.org/10.10 86/652731

Widoyoko, S. E. P. (2014). Teknik Penyusunan Instrumen Penelitian. Yogyakarta: Pustaka Pelajar.

Young, A. (2014). Street Art, Public City: Law, Crime and The Urban Imagination. New York: Routledge.

Zenebe, M. (2018). Taking the Forbidden Space: Graffiti and Resistance in Addis Ababa University, Ethiopia. Dalam Oinas E., Onodera H., \& Suurpää L. (Ed.), What Politics?: Youth and Political Engagement in Africa (95110). Leiden; Boston: Brill. https://www. jstor.org/stable/10.1163/j.ctv bqs5zx 